\title{
A Manufacturing Information Infrastructure to Link Team Based Design to Global Manufacture
}

\author{
R.I.M.Young, J.M. Dorador, J.Zhao, W.M.Cheung \\ Loughborough University, Loughborough, Leicestershire, LE11 3TU, U.K \\ Email: R.I.Young@lboro.ac.uk
}

Key words Information Infrastructures, team based design, global manufacture

\begin{abstract}
The moves towards team based design and global manufacture have led to the need for substantial improvements in the information support systems to aid the decision making of product designers and manufacturing engineers. This paper describes the findings of a research programme which has investigated the manufacturing information infrastructures required in both product and manufacturing models. A data model to represent global manufacturing facilities is proposed. Further a product data framework has been defined which can support multiple manufacturing views of a product. The machining and assembly processes have been used to illustrate these.
\end{abstract}

\section{INTRODUCTION}

While product model technology has advanced significantly in recent years, the current status of information model structures is limited when the multiple viewpoints of members of design teams need to be supported [1]. The limitation of current information infrastructures is extended further when the need to provide manufacturing information from multiple, globally located, facilities is considered. This paper discusses a research programme entitled 'Manufacturing Information Models' which explores the information infrastructures necessary to support the related activities of design for manufacture within a concurrent engineering environment and post design manufacturing planning [2].

While web based technology offers radical new approaches to accessing information [3], this information can only be of value if it can be interpreted and used by the appropriate decision-makers. This is particularly relevant where software applications utilise the information, as a clear definition of the information structure is essential. Hence there is a clear need for well- 
defined information infrastructures which can be used to aid the sharing of information across team based design and global manufacture.

The extensive work of the STEP community is progressing slowly towards standards for data exchange between CAD systems. They recognise that this is an initial stage in the progress towards information sharing in product design and manufacture systems [4]. The work reported in this paper started by assuming that information structures were the key to providing support to team based design. This has now developed to the belief that while product information structures can provide a basis for integrating team based activities, there is a clear need to link knowledge models into such a system.

Whilst the range of information and knowledge involved in supporting the range of decisions to be made in new product development is substantial, this paper focuses on manufacturing information and knowledge infrastructures. In particular it uses machining and assembly as example processes against which to explore information infrastructure requirements.

\section{THE MANUFACTURING INFORMATION MODELS CONCEPT}

\section{Informing Decision Makers}

The premise behind this paper is that computation systems in integrated design and manufacture should provide support to engineers by offering them quality information on which to base their decisions. This lies between the two extremes of automation, which typically provides inadequate results, and simple information retrieval routines, which are likely to result in information overload.

A further basis behind this paper is that if broad based, integrated solutions are to be provided, then there is a need to separate the range of information and knowledge from the software applications, communication mechanisms and people which will utilise it. The basic concept of the research is illustrated in figure 1.

\section{Supporting Design for Manufacture and Manufacturing Planning}

Both design for manufacture and manufacturing planning require an understanding of the manufacturing resources which are available to manufacture a product and how to use them. This is the case for single 
factory operations and for global supply chain systems. Within information systems there is therefore a need to define infrastructures which can capture information and knowledge about manufacturing. This can then be used by both design for manufacture and during manufacturing planning.

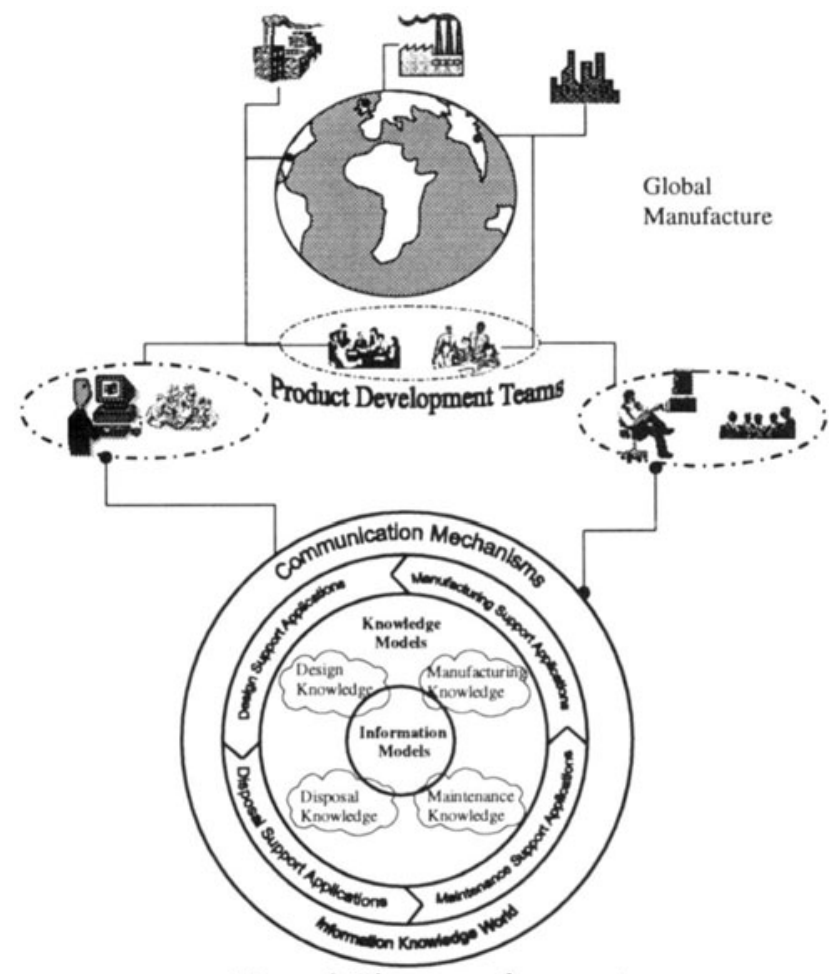

Figure 1. The research concept

Following the concurrent engineering philosophy leads us to perform design for manufacture as early as possible in the design process. It also raises an issue in terms of the relationship between design for manufacture and manufacturing planning. If manufacturing input is captured during design then how much remains to be done during manufacturing planning?

This paper proposes that ranges of manufacturing functions can be defined. The extent to which they are used during design is dependent on the extent to which particular manufacturing resources can be specified during the design process. Critically, the decisions made at any stage must be stored and managed in relation to the product under development.

Manufacturing functions to support design can provide general feedback on likely manufacturing processes or at a more detailed level can provide suggestions for design changes which improve the ease of manufacture of 
the product. Decisions at this detailed level require a clear understanding of manufacturing processes and are closely related to process planning.

Typical functions relating to detailed machining decisions can be listed as:

- Identify machining processes required

- Identify possible machine tools to be used

- Identify cutting tool types required

- Identify fixturing requirements

- Select machine tools

- Determine setup plans

- Determine cutting tools

- Determine cutting parameters

The order in which these are performed is largely sequential, with the earlier functions being open to suggest design changes. Performing the later functions in the list is dependent on having chosen the facilities to be used for manufacture.

\section{Manufacturing Information and Knowledge Requirements}

Manufacturing information can be classified in a number of different ways. It can be considered in terms of how to produce a particular product or in terms of how a particular enterprise can use its facilities to manufacture things. The former being part of a product model and the latter being a manufacturing model. Within the enterprise, information can be considered at a total enterprise level, or at specific factory, shop, cell or station levels. At each of these levels manufacturing information can be considered in terms of the resources which are available and the processes which can be performed. In addition knowledge of how these resources and processes can be used is important. For example, at the global level, knowledge about global manufacturing strategy can be captured. At the individual station or machine level, knowledge of how the machine can be used to perform particular processes can be held.

The information and knowledge about different manufacturing processes, e.g. machining and assembly, will be specific to the process. However, the structures used to hold this information and knowledge are a combination of generic and process specific relationships. The following section describes the product and manufacturing information structures which have been developed in the research to support both machining and assembly. 


\section{THE DESIGN OF A MANUFACTURING INFORMATION INFRASTRUCTURE}

\section{Product Model Structures}

A UML class diagram showing the general structure of a product model resulting from the work of this research is illustrated in figure 2. Typically product models are used as a source and repository for information concerning product geometry, dimensions and tolerances, and product material descriptions. These are captured under the Characteristics class in this work. A significant aspect of this figure is the Views class. This offers the facility of viewing and using the product model from different perspectives, which is critical to success if team based product development is to be successfully supported. In this example, the structure offers design views and manufacturing views. Views of the product which relate to particular manufacturing process views of the design can be held within the design views i.e. design for machining and assembly views. It is in these views that information relating to feature technology descriptions would be stored. The results of manufacturing designs made during the design process or during manufacturing planning are stored within the manufacturing views of the product.

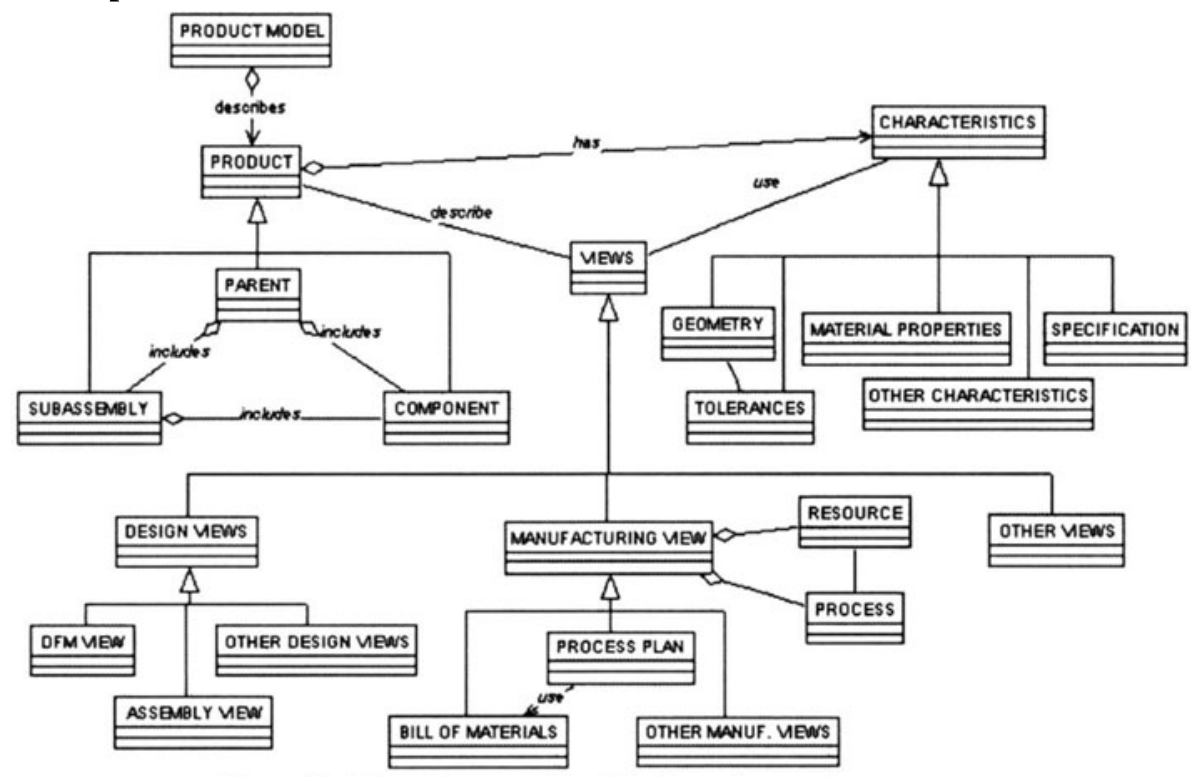

Figure 2. Class diagram of multi-viewpoint product structure 


\section{Manufacturing Model Structures}

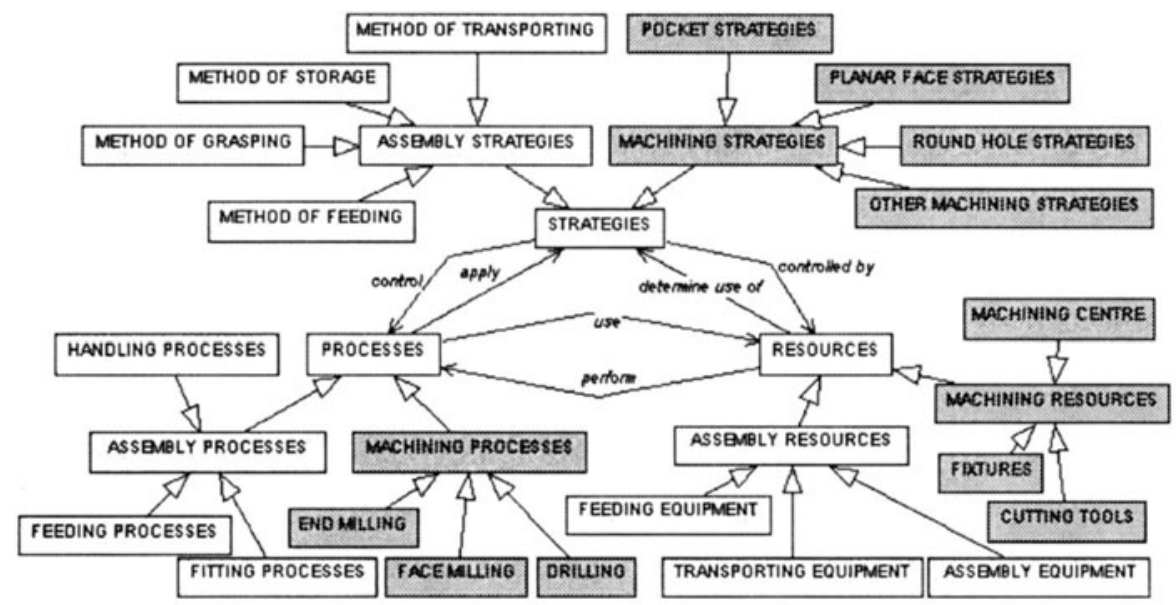

Figure 3. A class diagram for machining and assembly facilities

A general class structure in which to model a global manufacturing facility in terms of its resources, processes and strategies has been defined and can be found in [5]. A more detailed structure which can be used to capture machining and assembly capability is shown in figure 3 . This illustrates examples of particular resources, processes and strategies for the two processes in question. It also highlights that the relationships between the resources and processes can be defined and that the strategies provide definitions of how the resources and processes can be used. The strategies provide the knowledge element of the manufacturing model.

\section{Relationships between the model structures}

While the product model and manufacturing model can be considered to be two independent models, the relationships between the two model structures are interdependent. This interdependence is defined by the common information which the two models use, and by the relationships between information views.

Figure 4 illustrates how the resource and process structure in the manufacturing data model can be used in the product data model. The difference in the information content is that the manufacturing model captures all the processes and resources available, while the product model only captures those to be used in the manufacture of the product under development. 


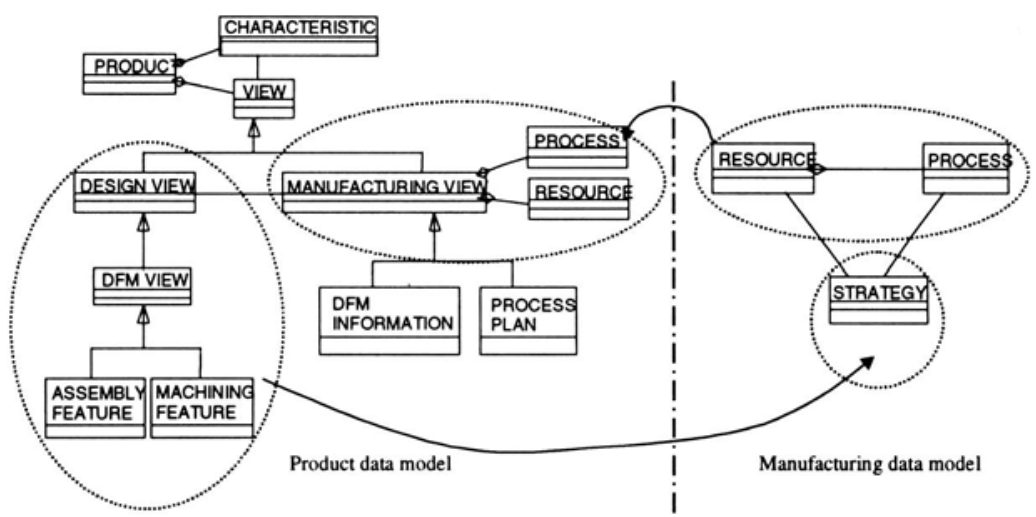

Figure 4. Relationships between product and manufacturing model structures

Figure 4 also illustrates that the relationship between design for manufacture views and manufacturing strategies is significant. The design for manufacture view captures the features which are significant on the product while the strategies class provides a representation of the ways in which a process can be used. This therefore provides a flexible means of relating feature based design descriptions to methods of manufacture.

\section{CONCLUSIONS}

Clearly defined information infrastructures are critical to the communication of useful information between product development team members, especially where integrated software solutions are required. This paper has provided a contribution to the definition of product model structures to support the multiple views of information required by product development teams. It has also shown how models of global manufacturing capability can be generated to cope with multiple, globally dispersed, manufacturing processes. Significant relationships between information model structures have been defined to support information sharing across team based design and global manufacture.

\section{ACKNOWLEDGEMENTS}

The authors wish to thank the EPSRC and their industrial collaborators. This work has been performed under grant number GR/L41493 entitled "Manufacturing Information Models". The research undertaken by J.M.Dorador is funded by UNAM and CONACYT, Mexico. 


\section{REFERENCES}

[1] Rosenman M. A., Gero J.S., (1999) Purpose and function in a collaborative CAD environment Reliability Engineering and system safety 64, 167-179.

[2] Young R.I.M, Canciglieri-Jnr O., Costa C.A., Dorador J.M., Zhao J., Cheung W.M. (2000) Information Support in an Integrated Product Development System Integrated Design and manufacture in Mechanical Engineering (IDMME'2000), CD-Rom paper MA3.1

[3] Tegel O. (2000) Information and communication technologies to support cooperation in the product development process. New Product Development and Production Networks, Ed. U.Jurgens, Pub. Springer, pp389-406. ISBN 3-540-64172-6.

[4] Fowler J, (1995). STEP for data management, exchange and sharing. (UK, Technology Appraisals), ISBN 1871802369.

[5] Zhao J, Cheung W.M, Young R.I.M, (1999) A manufacturing data model to support virtual enterprises, International Journal of Agile Management Systems, 1(3)150-158. 